\title{
MEMBANGUN BASIS DATA POSYANDU MENUJU INDONESIA SEHAT SENTOSA
}

\author{
Indrajani \\ Information Systems Department, School of Information Systems, Binus University \\ Jl. K.H. Syahdan No. 9, Palmerah, Jakarta Barat 11480 \\ indrajani@binus.ac.id
}

\begin{abstract}
The purpose of this research is to analyze and design a database to support Pos Pelayanan Terpadu (POSYANDU). Search data techniques implemented include interviews, documentation, observation, and literature study. Analysis and database design include conceptual, logical, and physical design. The result of this research is a database system that can save integrated data and POSYANDU information needs. Using the database system, PUSKESMAS can manage data of mother and baby's health and related transactions.
\end{abstract}

Keywords: system, database, posyandu, puskesmas

\begin{abstract}
ABSTRAK
Tujuan penelitian ini adalah menganalisis dan membangun basis data untuk mendukung kebutuhan informasi Pos Pelayanan Terpadu (POSYANDU). Metode yang digunakan adalah metode pengumpulan data dengan menggunakan teknik pencarian data yang meliputi wawancara, mempelajari dokumen, observasi, dan studi kepustakaan. Kemudian penelitian ini juga menggunakan metode analisis dan perancangan basis data yang mencakup perancangan basis data secara konseptual, logikal, dan fisikal. Hasil yang dicapai adalah sistem basis data yang mampu menyimpan data terintegrasi, dan memenuhi kebutuhan informasi POSYANDU. Simpulan yang dapat diperoleh dari penelitian ini adalah dengan adanya sistem basis data ini Pusat Kesehatan Masyarakat (PUSKESMAS) dapat mengelola data kesehatan ibu dan bayi serta transaksi-transaksi yang terkait dengan kesehatan ibu dan bayi tersebut.
\end{abstract}

Kata kunci: sistem, basis data, posyandu, puskesmas 


\section{PENDAHULUAN}

Data sangat dibutuhkan oleh tiap pengguna informasi. Data sangat membantu dalam pengambilan keputusan dan bermanfaat baik jangka pendek, menengah maupun jangka panjang. Demikian pula data yang terdapat pada Pos Pelayanan Keluarga Berencana - Kesehatan Terpadu (POSYANDU). Posyandu adalah kegiatan kesehatan dasar yang diselenggarakan dari, oleh, dan untuk masyarakat yang dibantu oleh petugas kesehatan.

Seperti yang dikutip dari Zulkifli (2003), posyandu merupakan wadah untuk mendapatkan pelayanan dasar terutama dalam bidang kesehatan dan keluarga berencana yang dikelola oleh masyarakat, penyelenggaraanya dilaksanakan oleh kader yang telah dilatih di bidang kesehatan dan $\mathrm{KB}$, di mana anggotanya berasal dari PKK, tokoh masyarakat dan pemudi.

Istilah posyandu bermula dengan dikeluarkannya konsep keterpaduan KB-kesehatan, di mana sebelum adanya posyandu tidak ada keterpaduan baik lintas program maupun lintas sektoral yang menyangkut pelayanan KB-kesehatan di masyarakat. Gagasan ini muncul pertama kali dari dir.Jen Binkesmas dan pada saat itu lebih dikenal dengan gagasan bapak Dr. Soyono Yahya, MPH yang disebut dengan posyandu. Pada prinsipnya konsep ini sangat sederhana, mudah pelaksanaan dan dapat meningkatkan efisiensi pelayanan seta besar menfaatnya. Dalam pelaksanaanya diperlukan kerja sama lintas sektoral dan lintas program, untuk itu pada tahun 1985 dikelurkan instruksi bersama antara Mendagri, Menkes dan Kepala BKKBN (Zulkifly, 2003).

Peneliti melihat cara kerja yang diterapkan masih manual di sebuah Posyandu, mulai dari pendaftaran, pencatatan hasil diagnosa, pencatatan obat yang diberikan. Data direkam pada sebuah kartu berobat yang dibuat per ibu dan anak dan disimpan pada Kelurahan, Kepala Kader,dan Puskesmas di mana ibu dan anak tersebut berobat. Artinya bila ibu dan anak ingin berobat di Posyandu terdekat lainnya, data dan informasi pada Posyandu sebelumnya tidak dapat diketahui dan harus dicatat mulai dari pendaftaran identitas ibu dan anak, keluhan-keluhannya, dan harus menceritakan kembali riwayat sakit yang pernah dideritanya dan dokter akan menganalisis kembali setiap keluhan-keluhan dari ibu dan anak dari awal. Hal ini mengakibatkan berulangnya sebuah proses yang sama.

Data dan informasi kebutuhan akan obatpun harus tersedia dan terkini agar jangan sampai kekurangan stok obat yang dapat mengakibatkan kesulitan ibu dan anak untuk memperoleh obat dan berakibat fatal terhadap kesembuhan ibu dan anak. Berdasarkan uraian tersebut, diperlukan sekali pembangunan basis data guna menunjang pengelolaan Posyandu sesuai dengan kondisinya dan mengatasi kesulitan perolehan data, di mana Posyandu merupakan ujung tombak pelayanan kesehatan di Indonesia.

\section{METODE}

Metode penelitian yang digunakan adalah metode pengumpulan data, metode analisis, dan metode perancangan basis data. Teknik yang digunakan dalam metode pengumpulan data ini mencakup antara lain wawancara, mempelajari dokumen, observasi, dan studi kepustakaan (Indrajani, 2011, 64 ). Wawancara dilakukan pada bagian-bagian yang akan menggunakan sistem basis data yang diusulkan, yaitu kader Posyandu, ibu hamil atau nifas, orang tua bayi, Puskesmas, Kelurahan, dan Dinas Kesehatan. Pertanyaan-pertanyaan yang akan ditanyakan akan disiapkan terlebih dahulu sebelum wawancara berlangsung. Sifat yang akan digunakan adalah gabungan antara pertanyaan tertutup dan terbuka. Untuk mendapatkan data dan informasi mengenai kebutuhan pengguna secara 
lengkap, maka dilakukan juga pengumpulan dokumen-dokumen berupa contoh-contoh formulir seperti registrasi ibu dan anak, pendataan transaksi yang terjadi pemeriksaan, pengobatan, laporan-laporan medis ibu dan anak, buku ibu dan anak, dan daftar-daftar seperti kader posyandu dan ibu serta anak. Selain itu juga dilakukan observasi langsung ke lapangan agar memahami Posyandu secara nyata.

Metode berikutnya adalah analisis, yaitu analisis kebutuhan data dan kelemahan dari sistem yang sedang berjalan. Dari hasil analisis yang dilakukan terhadap suatu Posyandu maka dapat dirumuskan beberapa masalah yaitu kesulitan pencarian data-data ibu dan anak, kader Posyandu, obat maupun transaksi-transaksi pemeriksaan dan pengobatan. Posyandu menyimpan data-data ibu dan anak yang berobat di Posyandu tersebut. Selain itu Posyandu juga menyimpan data-data transaksi yang telah dilakukan Posyandu sehingga semakin lama data-data yang disimpan semakin banyak. Akibatnya, pengguna informasi membutuhkan waktu yang lama untuk mendapatkan informasi yang dibutuhkan. Masalah lainnya adalah kesulitan membuat dan menyajikan laporan, ibu dan anak berobat, dan transaksi yang cukup banyak dilakukan secara manual sehingga membutuhkan waktu yang cukup lama untuk mengolah informasi yang dibutuhkan. Kemudian belum adanya sistem keamanan data. Data-data hanya tercatat pada buku-buku dan berkas-berkas sehingga data-data penting posyandu dapat dilihat, diganti dan diambil oleh siapa saja. Lalu kesalahan pemasukan data. Sistem yang berjalan pada Posyandu masih manual, ada kemungkinan kesalahan manusia penulisan data.

Metode terakhir yang digunakan dalam penelitian ini adalah metode perancangan basis data. Dalam metode ini akan dibagi menjadi tiga tahap, yaitu yaitu perancangan basis data konseptual, perancangan basis data logikal, dan perancangan basis data fisikal. Adapun perancangan basis data konseptual adalah perancangan basis-data konseptual proses membangun suatu model dari informasi yang digunakan dalam sebuah organisasi dalam hal ini Posyandu, terbebas dari segala pertimbangan fisikal. Perancangan basis-data logikal yaitu proses membangun suatu model dari informasi yang digunakan dalam sebuah Posyandu berdasarkan sebuah model data yang spesifik tetapi terbebas dari DBMS tertentu dan pertimbangan fisikal lainnya. Tahapan ketiga yaitu perancangan basis-data fisikal adalah proses menghasilkan sebuah deskripsi dari implementasi basis-data pada media penyimpanan sekunder yang mendeskripsikan relasi dasar, organisasi file, dan indeks yang digunakan untuk mengakses data secara efisien, dan setiap batasan integritas terkait dan ukuran-ukuran keamanan.

\section{HASIL DAN PEMBAHASAN}

Berdasarkan analisis terhadap permasalahan dan prosedur yang berjalan di dalam bagian Posyandu, terdapat beberapa usulan pemecahan untuk masalah-masalah tersebut, yaitu menyimpan semua dokumen ibu dan anak yang diperlukan selama proses pemeriksaan dan pengobatan ke dalam suatu sistem basis data yang terintegrasi. Kemudian masing-masing kader Posyandu diberikan hak akses pada data tersebut sesuai dengan wewenangnya masing-masing sehingga memudahkan proses periksaan data. Lalu merancanga suatu sistem basis data terintegrasi yang memungkinkan kader Posyandu, Kelurahan, Puskesmas, dan Dinas Kesehatan untuk dapat melihat atau mengubah langsung status data dan menyimpannya ke dalam sistem.

Setelah itu melakukan penyimpanan data yang diperlukan untuk pembuatan laporan ke dalam suatu sistem basis data terintegrasi. Dengan demikian, data tersebut dapat dengan mudah dipanggil ketika diperlukan untuk pembuatan laporan. Kemudian merancang suatu sistem basis data yang terintegrasi sehingga memungkinkan kader Posyandu untuk membuat laporan dan mengirimkannya dalam bentuk softcopy melalui sistem. Dengan demikian dapat mengurangi jumlah laporan yang tercecer, rusak, dan hilang. 
Ada empat prosedur yang perlu diperhatikan dalam Posyandu, yaitu registrasi ibu hamil dan bayi, pemeriksaan kehamilan dan nifas ibu hamil, pemeriksaan bayi, dan pelaporan ibu hamil dan bayi. Pada Gambar 1 terlihat ibu hamil dan anak mengisi formulir pendaftaran yang diberikan oleh kader Posyandu. Setelah formulir itu terisi, kader Posyandu akan memberikan kartu Ibu dan buku KIA.

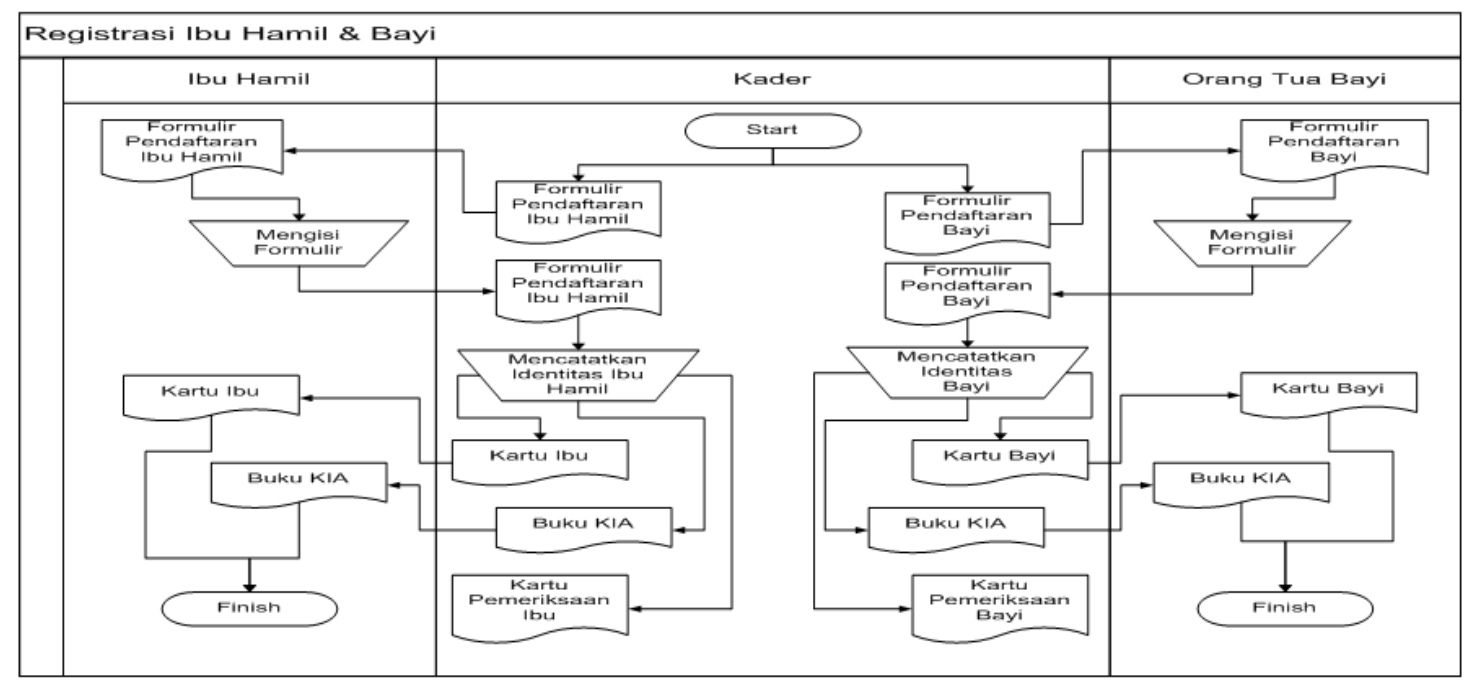

Gambar 1 Proses registrasi ibu hamil dan anak

Pelaporan ibu hamil dan bayi (Gambar 2) dilakukan oleh kader Posyandu pada Puskesmas dan Kelurhan. Jenis-jenis laporan yang dibuat adalah laporan pemeriksaan bayi, pemeriksaan ibu hamil, laporan vit A, laporan imunisasi, dan laporan obat.

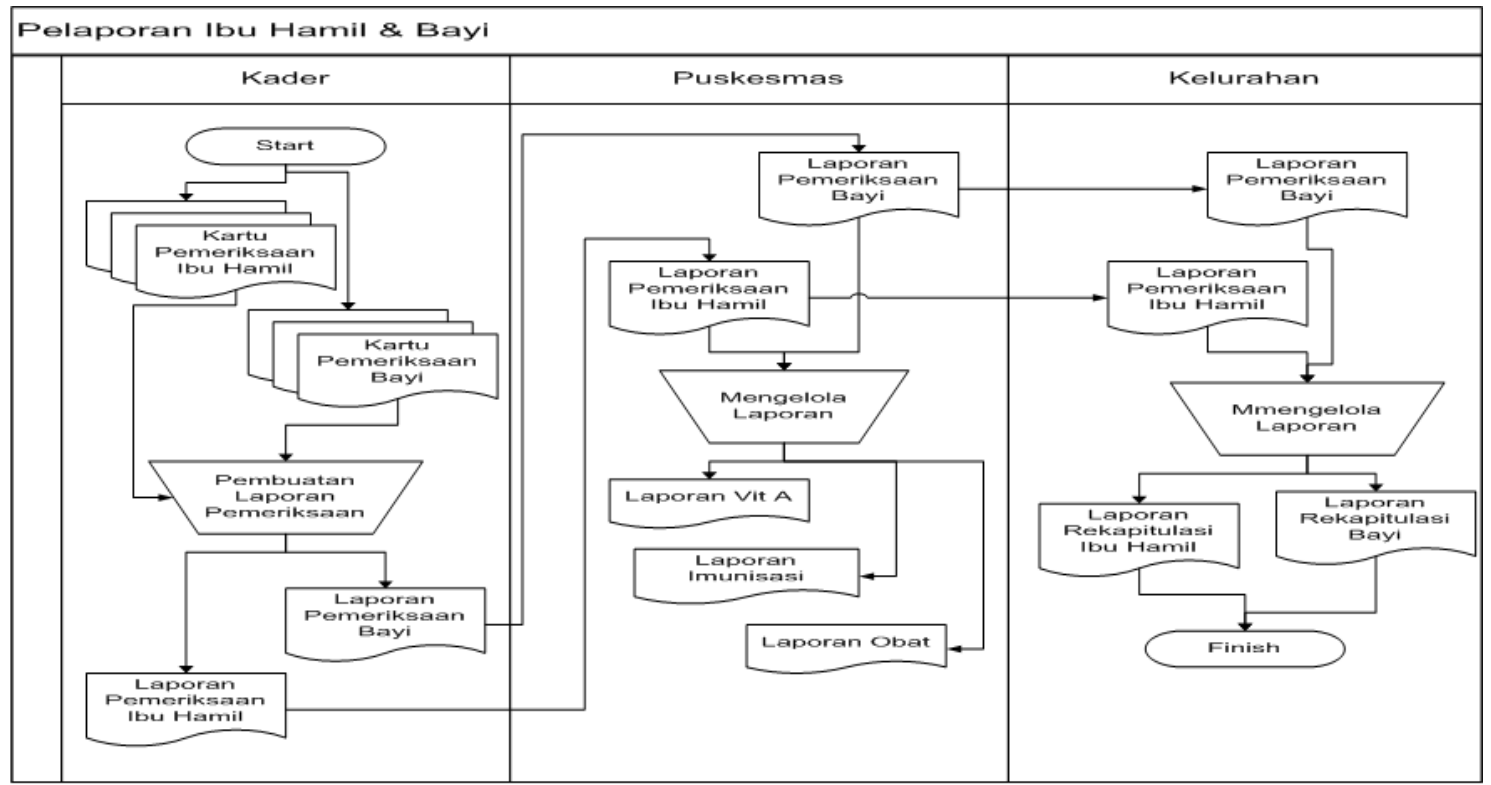

Gambar 2 Proses pelaporan ibu hamil dan bayi

Setelah melakukan menganalisis proses pada Posyandu, maka tahapan yang dilakukan adalah perencanaan basis data. Pada tahap ini dinyatakan tujuan dari perancangan basis data. Perancangan 
Basis Data Posyandu Mawar Putih bertujuan untuk menyimpan dan mengelola data diri dan data kesehatan ibu hamil, bayi/balita serta untuk memudahkan kader dalam melaporkan data kesehatan ibu hamil, bayi/balita ke kelurahan, dan puskesmas.

Pada Gambar 3 tampak Kepala Kader berhubungan dengan kader, kemudian Puskesmas berhubungan dengan kader. Lalu Kelurahan berhubungan dengan kader. Ibu Hamil/Nifas berhubungan dengan kader. Terakhir adalah Orangtua Bayi Balita berhubungan dengan kader.

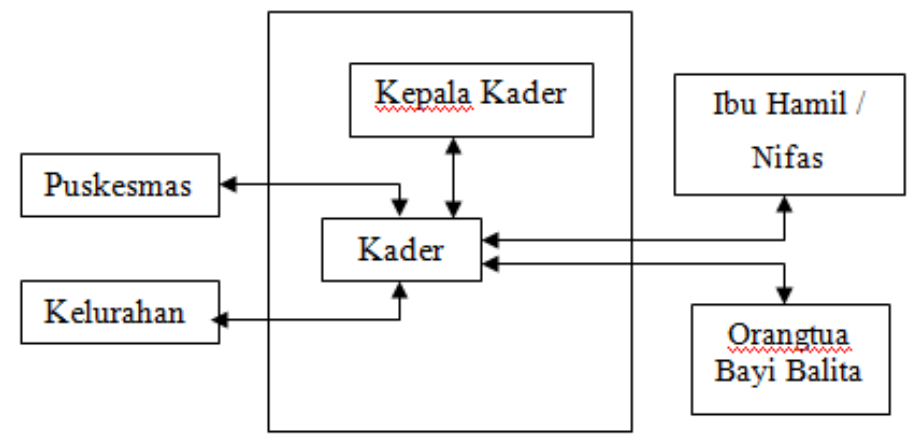

Gambar 3 Batasan sistem

\section{Perancangan Konseptual}

Proses membangun sebuah rancangan informasi yang digunakan dalam suatu perusahaan yang bebas dari pertimbangan fisikal. Perancangan melibatkan pembuatan suatu model data konseptual dari bagian perusahaan. Model data dibuat dengan menggunakan informasi yang didokumentasi dalam spesifikasi kebutuhan pengguna. Perancangan basis data konseptual secara keseluruhan bebas dari rincian implementasi seperti software DMBS, program aplikasi, bahasa pemrograman, hardware platform, atau permasalahan fisikal lainnya. Langkah-langkah dalam perancangan basis data konseptual, antara lain mengidentifikasi tipe entitas, mengidentifikasi tipe relationship, identifikasi dan asosiasi atribut suatu entitas, menentukan domain atribut, identifikasi candidate key dan primary key suatu entitas, mengecek model redundansi, dan validasi model konseptual terhadap transaksi pengguna. Di akhir tahap perancangan basis-data konseptual ini, dihasilkan sebuah model data konseptual yang benar-benar mewakili view. Adapun model data konseptual yang dihasilkan adalah seperti yang terlihat pada ERD berikut ini (Gambar 4):

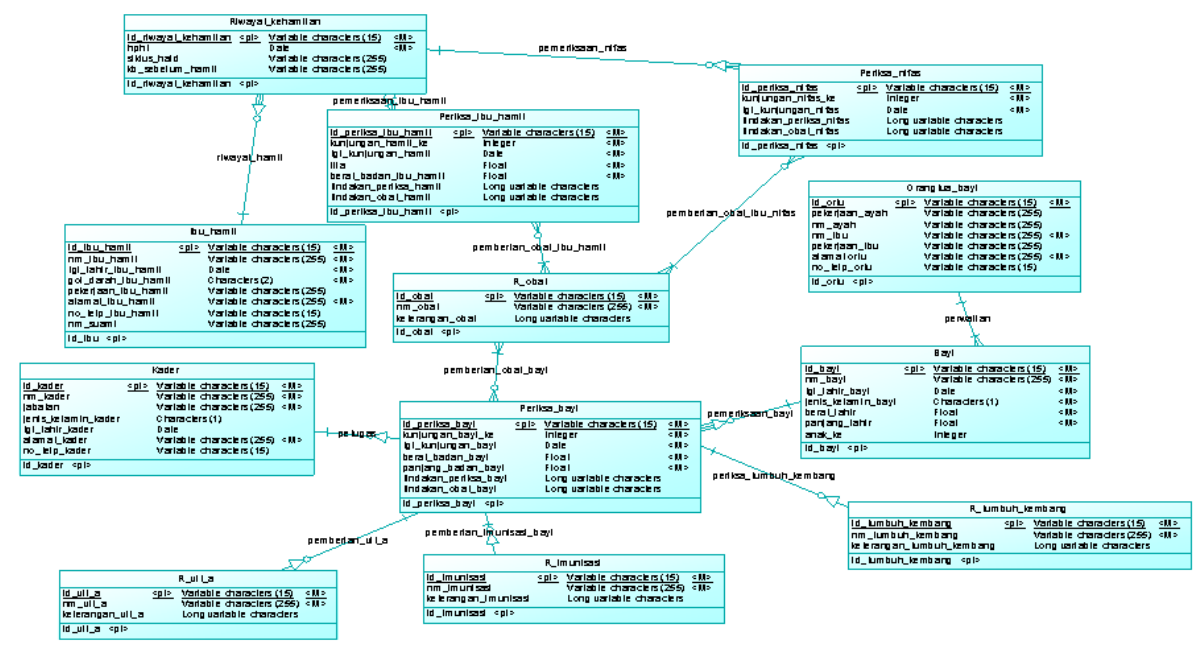

Gambar 4 ERD model data konseptual 


\section{Parancangan Logikal}

Proses membangun sebuah rancangan informasi yang digunakan dalam suatu perusahaan berbasis data pada rancangan data yang spesifikasi tetapi masih bebas dari penentuan DBMS dan pertimbangan fisikal yang lain. Pada proses perkembangan model data logikal, model diuji dan divalidasi terhadap kebutuhan pengguna. Tujuan dari tahapan ini adalah untuk menghilangkan fiturfitur yang tidak kompatibel dengan model relasional. Pada akhir tahapan ini dihasilkan satu model data logikal. Adapun langkah-langkah yang dilakukan dalam merancang basis-data logikal, yaitu menurunkan tabel untuk model data logikal, memvalidasi tabel menggunakan normalisasi, memvalidasi tabel terhadap transaksi pengguna, memeriksa batasan integritas, dan me-review model data logikal lokal dengan pengguna

\section{Parancangan Fisikal}

Perancangan basis-data fisik merupakan proses untuk memutuskan bagaimana struktur logikal diimplementasikan secara fisik (sebagai relasi/ tabel) ke target DBMS. Adapun langkah-langkah yang dilakukan dalam perancangan basis-data fisikal, yaitu merancang relasi dasar, merancang representasi dari data turunan (derived data), merancang batasan umum (general constraints), memilih indeks, memperkirakan kebutuhan disk space, dan merancang Mekanisme Keamanan (Gambar 5).

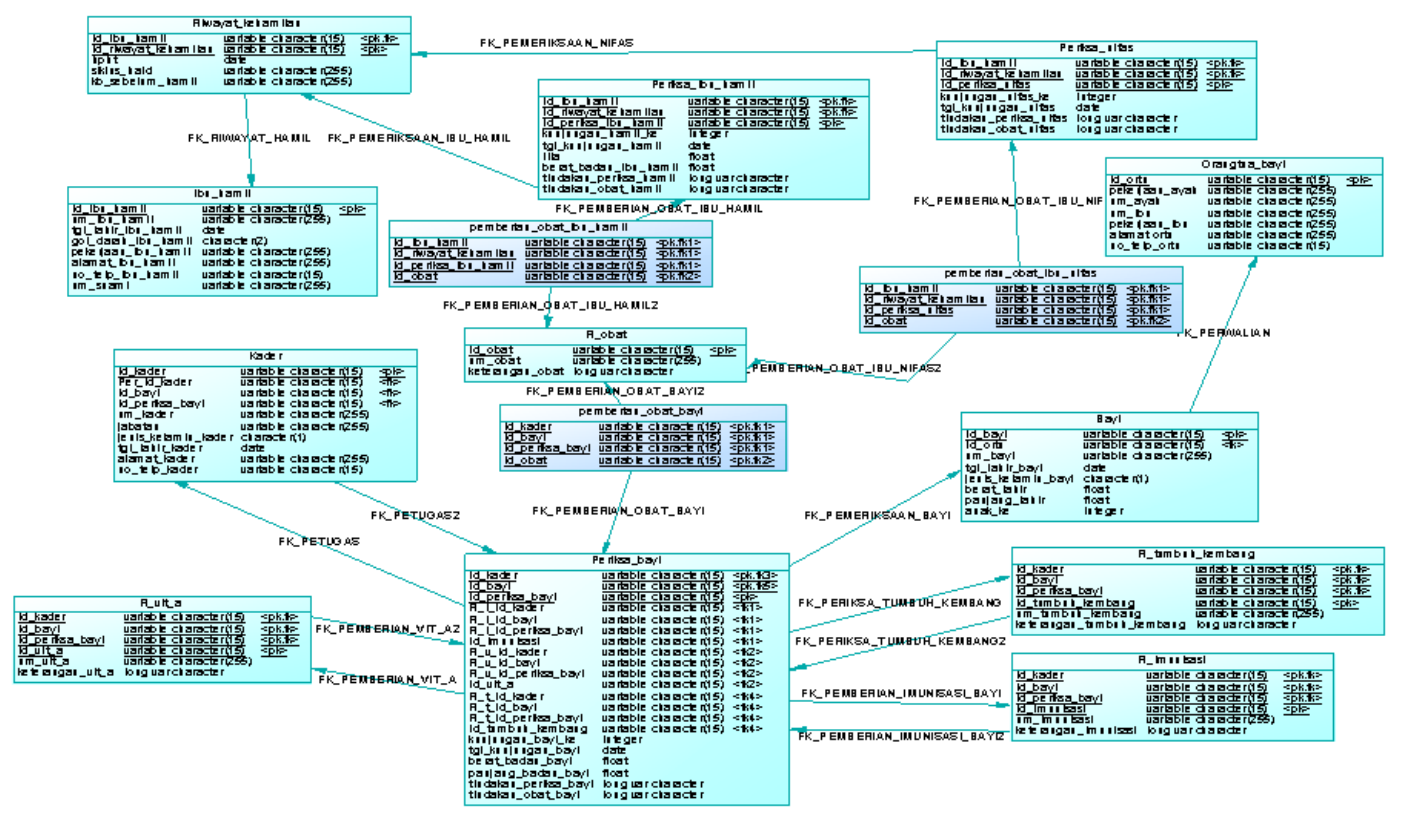

Gambar 5 ERD model data fisikal

Dari hasil ERD tersebut maka dibentuklah tabel-tabel (Tabel 1 - 3) sebagai berikut: 
Tabel 1 Tabel Ibu_Hamil

\begin{tabular}{|l|l|l|c|}
\hline \multicolumn{1}{|c|}{ Nama } & \multicolumn{1}{|c|}{ Kode } & \multicolumn{1}{c|}{ Tipe Data } & Mandatory \\
\hline id_ibu_hamil & ID_IBU_HAMIL & Variable characters (15) & x \\
nm_ibu_hamil & NM_IBU_HAMIL & Variable characters (255) & x \\
tgl_lahir_ibu_hamil & TGL_LAHIR_IBU_HAMIL & Date & x \\
gol_darah_ibu_hamil & GOL_DARAH_IBU_HAMIL & Characters (2) & x \\
pekeriaan_ibu, hamil & PEKERJAAN_IBU_HAMIL & Variable characters (255) & x \\
alamat_ibu_hamil & ALAMAT_IBU_HAMIL & Variable characters (255) & Variable characters (15) \\
no_teld_ibu_hamil & NO_TELP_IBU_HAMIL & Variable characters (255) & \\
nm_suami & NM_SUAMI & &
\end{tabular}

Tabel 2 Tabel Bayi

\begin{tabular}{|l|l|l|c|}
\hline \multicolumn{1}{|c|}{ Nama } & \multicolumn{1}{|c|}{ Kode } & \multicolumn{1}{c|}{ Tipe Data } & Mandatory \\
\hline id_bayi & ID_BAYI & Variable characters (15) & x \\
nm_bayi & NM_BAYI & Variable characters (255) & x \\
tgl_lahir_bayi & TGL_LAHIR_BAYI & Date & x \\
jenis_kelamin_bayi & JENIS_KELAMIN_BAYI & Characters (1) & x \\
berat_lahir & BERAT_LAHIR & Float & x \\
panjang_lahir & PANJANG_LAHIR & Float & x \\
anak_ke & ANAK_KE & Integer & \\
\hline
\end{tabular}

Tabel 3 Tabel Kader

\begin{tabular}{|c|c|c|c|}
\hline Nama & Kode. & Tipe Data & Mandatory \\
\hline id kader & ID_KADER & Variable characters (15) & $\mathrm{x}$ \\
\hline nm,kader & NM_KADER & Variable characters $(255)$ & $\mathrm{x}$ \\
\hline jabatan & JABATAN & Variable characters (255) & $\mathrm{x}$ \\
\hline jenis, kelamin ka der & JENIS_KELAMIN_KADER & Characters (1) & \\
\hline tglahir kader & 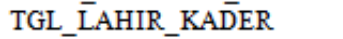 & Date & \\
\hline alamat kader & ALAM̄MAT_KĀDER & Variable characters (255) & $\mathrm{x}$ \\
\hline no telp kader. & NO TELP_KADER & Variable characters (15) & \\
\hline
\end{tabular}

Selain tabel-tabel tersebut, dihasilkan pula tabel untuk menyimpan pemeriksaan ibu hamil, pemeriksaan bayi, riwayat kehamilan, orang tua bayi, obat, tumbuh berkembang, imunisasi, dan vitamin.

\section{Pemilihan Organisasi File}

Pemilihan organisasi file bertujuan untuk menentukan organisasi file yang efisien untuk masing-masing basis relasi. Pemilihan organisasi file diambil berdasarkan organisasi file yang digunakan oleh SQL 2008.

\section{Pemilihan Indeks}

Untuk meningkatkan performa dari sistem sewaktu mencari data, maka dibuatlah index pada tabel-tabel yang telah dibuat. Indeks dibuat berdasarkan field yang sering digunakan dalam proses pencarian. Berikut ini adalah daftar indeks untuk masing-masing tabel yang ada.

\section{Rancangan Mekanisme Keamanan}

Suatu basis data merepresentasikan informasi penting bagi perusahaan dan keamanan dari informasi merupakan faktor penting. Dalam keamanan ada dua tipe keamanan, yaitu keamanan sistem dan keamanan data. Keamanan sistem mengatur pengaksesan dan penggunaan basis data. Caranya adalah dengan membuat halaman login sebelum masuk ke halaman utama dari sistem. Dalam halaman 
login, user diminta untuk memasukkan username dan password. Sehingga user yang tidak memiliki username tau tidak memiliki password maka tidak akan bisa masuk ke sistem. Sedangkan untuk keamanan data, berhubungan dengan relasi basis data (tabel atau relasi) dan aksi yang user lakukan terhadap relasi tersebut, misalnya aksi pemilihan, pengisian, pengubahan, dan penghapusan data. Berikut ini akan ditampilkan matriks referensi silang antara user dan relasi. Tujuannya adalah untuk membatasi hak akses user terhadap relasi yang ada.

\section{Perancangan Aplikasi}

Di dalam perancangan aplikasi terdapat rancangan struktur menu-menu. Kemudian dilanjutkan dengan pembuatan State Transition Diagram (STD), rancangan layar, dan spesifikasi prosesnya. Pada rancangan pendaftaran bayi/balita (Gambar 6), ID bayi tidak boleh kosong. Demikian pula dengan nama bayi, jenis kelamin, tanggal lahir, berat lahir, panjang lahir dan anak ke. Seluruhnya harus diisi. Data yang diisi akan disimpan pada tabel bayi. Dalam rancangan pemeriksaan ibu hamil (Gambar 7), nama ibu akan tampil otomatis saat ID ibu dimasukkan. Lalu untuk kunjungan ke harus diisi, demikian pula tanggal kunjungan. Setelah itu tindakan pemeriksaan dan tindakan obat serta nama pemeriksa harus diisi. Rancangan ini akan berhubungan dengan tabel pemeriksaan ibu hamil.

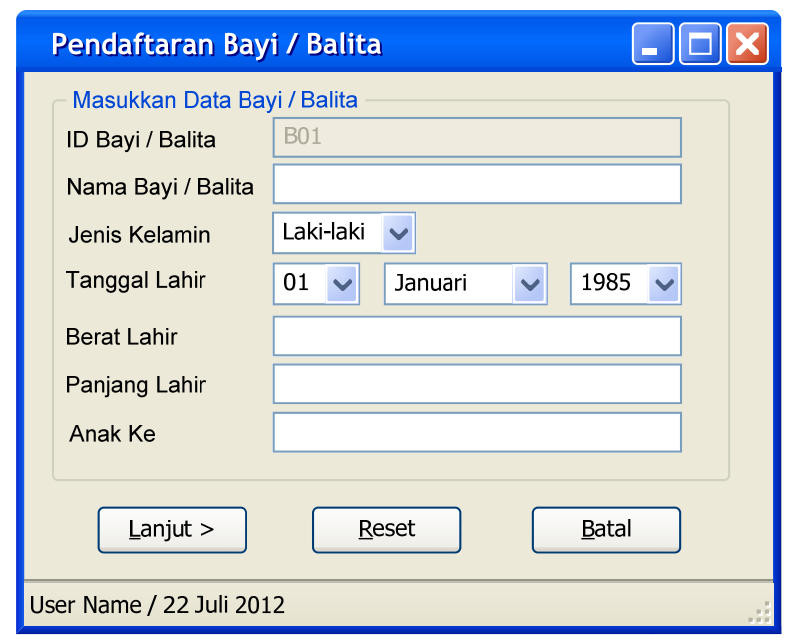

Gambar 6 Rancangan pendaftaran bayi/balita

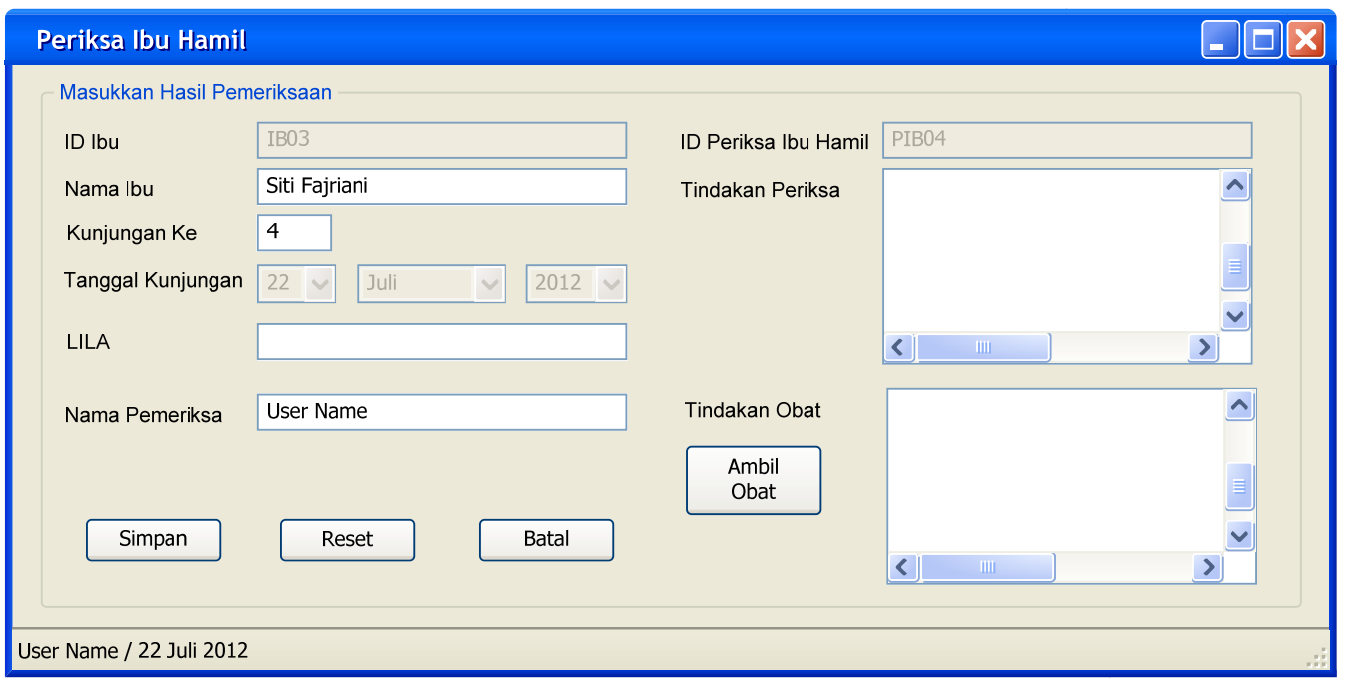

Gambar 7 Rancangan pemeriksaan ibu hamil 


\section{PENUTUP}

Basis data Posyandu yang dibangun merupakan dasar atau cikal bakal dari pembangunan basis pelayan kesehatan selanjutnya yaitu klinik, Puskesmas, dan rumah sakit. Perancangan basis data Posyandu menghasilkan beberapa tabel master dan tabel transaksi antara lain tabel ibu_hami, tabel bayi, tabel kader, tabel untuk menyimpan pemeriksaan ibu hamil, pemeriksaan bayi, riwayat kehamilan, orang tua bayi, obat, tumbuh berkembang, imunisasi, dan vitamin.

Melihat efesiensi pelayanan dan manfaat Posyandu, tentunya upaya yang telah berjalan harus ditingkatkan agar anggota masyarakat dapat menolong diri dan keluarganya dalam bidang kesehatan juga yang lebih penting dengan mengikuti kegiatan Posyandu secara teratur bagi yang mempunyai balita. Tetnunya seluruhnya itu didukung oleh basis data dengan sistem informasi Posyandu.

\section{DAFTAR PUSTAKA}

Indrajani. (2011). Bedah Kilat 1 Jam: Pengantar Dan Sistem Basis Data. Jakarta: Elex Media Computindo.

UNICEF. (2002). IDS: Evaluation of Posyandu Revitalization. Diakses dari http://www.unicef.org/evaldatabase/index_19007.html

Zulkifly. (2003). Posyandu dan Kader Kesehatan. Diakses dari http://repository.usu.ac.id/bitstream/123456789/3753/1/fkm-zulkifli1.pdf. 